\section{THE IMMERSIVE GUITAR PROJECT: IMAGINING POSSIBILITIES FOR ENRICHING AUDIENCE EXPERIENCE THROUGH ARCHITECTURAL INNOVATION}

Jocelyn Wolfe*, Vanessa Tomlinson and Karin Schaupp, Queensland Conservatorium Research Centre, Griffith University, Queensland, Australia.

*Email: j.wolfe@griffith.edu.au.

See https://direct.mit.edu/leon/issue/54/4 for supplemental files associated with this issue.

Submitted: 18 September 2020

\section{Abstract}

This article introduces The Immersive Guitar (TIG) Project, a proposed sonic performance installation that doubles as an intimate acoustic venue. The TIG Project responds to several needs, highlighting relations between place and performance, music and architecture. The needs concern a rarity of suitable, intimate spaces for acoustic performance and an appeal for more creative solutions in the provision of such spaces, which would afford novel ways of accessing performing arts experiences. This article introduces the proposition and provides project background and rationale.

\section{The Proposition}

The Immersive Guitar (TIG) Project aims to build a new musical instrument that doubles as a performance space. Designed on the acoustic principles of a guitar, this invention seeks to expand listeners' experience of resonant spaces in intimate concert settings, provide greater public access to unique performing arts venues and advocate for innovation in the design of performing arts spaces. TIG is listened to from inside the body of a guitar-building (built at the scale of 11.5:1), giving audience members the rare experience of "inhabiting" an acoustic instrument.

With the intent to hold around 25 audience members, the instrument lies on its back with the audience seated on a bench that hugs the internal outline of the guitar's "belly," with light shining in through the open sound hole two meters above. The guitar-shaped performance space/shell has three sound boxes installed in the ceiling to simulate the sonic and visual experience of being inside a guitar with the strings strung overhead (Fig. 1). The acoustic sound is generated from the luthier-designed sound boxes activated by a live performer plucking the nylon strings at the sound hole; each sound box supports two strings. Experiments indicate that the sound boxes will be staggered to accommodate the varying string lengths $(1.8-2.9 \mathrm{~m})$ and to reduce the individual string diameter (ranging from $1.6 \mathrm{~mm}$ to $3 \mathrm{~mm}$ ). In this way we address the issue of similitude caused by simply scaling up a soundboard and strings; the geometry of the guitar is scaled up, but the acoustic workings are somewhat transformed, inspired by the different zones of vibration (according to pitch) on a handmade concert guitar with an active top.

By tensioning the strings at $35 \mathrm{~kg}$ per string, we can achieve frequencies corresponding to a six-string contrabass classical guitar (one octave below a guitar). Amplitude measured in the experiments demonstrates sufficient volume for the internal space, reinforced by the resonant construction of the shell. Further, with the sound boxes facing down into the space, there is a direct "line of sight" between the ear of the audience and the heart of the guitar (sound boxes). The result is a "sound-engine" of a guitar-like instrument in the ceiling and a resonating chamber and performance space at floor level.

The project is the inspiration of guitarist Karin Schaupp and percussionist Vanessa Tomlinson of Queensland Conservato-

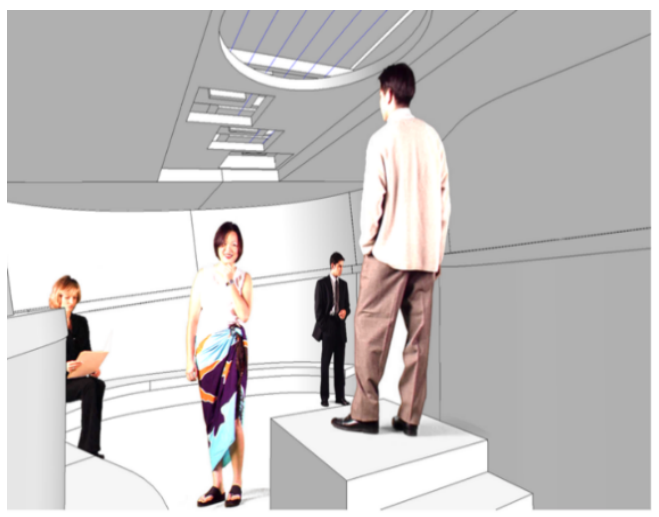

Fig. 1. Section of the Immersive Guitar: perspective view of the interior showing performance space, strings, sound chambers and audience. (C) Conrad Gargett)

rium Research Centre, Griffith University. It commenced in April 2019 with a professional design team including luthier and instrument design consultant Jim Redgate, architect Bruce Wolfe, structural engineer Hassan Karampour and research assistant Jocelyn Wolfe, with 3D model assistance from Conrad Gargett. TIG is designed to be portable on a 3-ton truck, erected onsite, presented indoors or outdoors, and is approximately $5.2 \mathrm{~m}$ long $\times 4.3 \mathrm{~m}$ wide $\times 2 \mathrm{~m}$ high, the neck being an additional $3 \mathrm{~m}$ long.

The project extends twentieth-century innovations in performance space design by Le Corbusier and Xenakis wherein instrument design, as well as inventive approaches to musical composition, inform the built outcome. There is richness in the inspirations and discoveries that have come out of this connection between music and architecture, especially concerning the affinities between the tectonics of buildings and musical instruments [1]. While this is one application of TIG, the motivation for taking audiences into what is essentially a big guitar is also to draw attention to the significance of acoustic instruments.

The design is inspired by an acoustic guitar's percussive as well as harmonic and melodic capabilities, allowing the audience to see every detail-and effort-of sound-making happen in front of their eyes. TIG will feature bespoke music composed by Tomlinson that explores possibilities opened up by this unique mobile, immersive building, including tuning systems and material qualities. Significantly, unlike other largescale string instrument/building projects, there is no use of electronics in TIG.

Two parameters define TIG: that the space can be inhabited, offering a distinctive internal listening experience, and that the structure can be "played," offering the invention of a new instrument, a new performative approach and new compositional possibilities. TIG will continue the dialogue between music and architecture through questioning site, form, purpose and materials, as well as through the audience experience.

\section{Rationale}

The Immersive Guitar Project provides an opportunity to explore the broader field of collaborations in music and architecture and the place of these collaborative projects in our performing arts culture. The project builds on identified needs [2], involving relations between place and performance that motivate further investigation. These can be summarized as needs for:

- Experiences in highly experimental alongside highly conventional places

- A sense of intimacy with experience 
- Different ways of accessing art experiences

- A wider range of places for performance, including the outdoors

- A greater level of engagement by town planners and architects addressing relationships between place, performance and aesthetic experience

- Resolving an issue of inflexibility in relationship between place and performance

The design of dedicated concert halls is commonly informed by the science of acoustics, which can result in a uniformity of experience. Finding alternatives to these larger venues is challenging. At Melbourne Festival 2011, the city hosted the first small, portable venue in Australia, Quartetthaus, purpose-built for string quartet performance and commissioned by the Australian National Academy of Music. Influenced by the intimacy of the Western string quartet, the architects celebrate the "chamber" in chamber music. The venue holds just 52 seats in two circles around a slowly revolving central stage, meaning no audience member is more than two meters from the performers. This accentuates the visceral theater of live acoustic performance and "dissolves" the performer/listener divide [3].

The interest in smaller venues can be seen as a sign of the times, with even smaller venues including private homes and small galleries becoming popular for concerts in Australia and internationally [4]. This trend suggests an audience looking for enhanced experiences of live acoustic music performance - not only intimate, but novel.

While intimacy is a consideration in TIG, inspiration, design, innovation, location and materials are also contributing factors to the overall listening experience. Critically, there is a philosophical commitment in this project to highlighting technology and innovation in venue design without the use of amplification: using the form and fabrication of an oversized acoustic guitar shell as a resonator, immersing the audience in bodily listening [5], highlighting properties of materials and the dynamic interaction of player with instrument, to assist in the sonic transmission.

TIG focuses attention on properties of sound through the raw materials of the structure - the aural architecture of the space [6]. This entirely acoustic environment brings the listener into the moment, with attention to place and proximity to the embodied experience of the performers. Effectively, this kind of immersive experience helps the listener gain a visceral understanding of the instrument from the performer's acuity. The acoustic guitar is an unsullied vehicle for this experience, and the repertoire of the solo acoustic guitar is a prime example of music best heard in such intimate, acoustic environments.

Intimacy provides "liveness" [7]. This is why we physically attend performances rather than simply listen to music on the radio or streaming services [8]. Intimacy is a key to the listening experience of solo or chamber music, alongside the experience of the space, audience connection with the players and players' connection with each other. Wilschut notes in her doctoral study [9] that audience members commented on how the intimate size of the concert space enhanced the concert experience, one of the reasons she determines that many artists and promoters are recreating the intimate concert experience in small venues. There is a sense that uniqueness of experience is desirable.

Uniqueness can also be found in the architecture of a venue, including architecture inspired by instrument design. Xenakis famously stated that concert hall designers should seek inspiration in the fine art of instrument-building [10]. His theories are of interest not only because he was both a composer and an architect but also because his designs embraced new auditory experiences. In designing an experimental concert hall for the City of Music project in Paris in 1984, in collaboration with French architect Jean-Louis Véret, Xenakis treated the enclosed spaces of an instrument as a spatial envelope. The structure was conceived as an independent element under a large concrete shell. Sterken [11] observes a number of significant architectural features that would enable various seating topographies and three-dimensional distribution of the audience, the musicians and the technical apparatus. Varying curvatures would allow nonpolarized reflection of the sound waves for homogeneous diffusion of the sound. The empty space under the shell would serve as a resonating chamber. In this respect, not only did Xenakis take inspiration from the organic geometry of musical instruments, but his building was also designed to function as one. Ultimately, this is the goal of the experimental structure of TIG.

Effectively, TIG proposes a place among a growing body of experimental work that celebrates connections between music and architecture [12]. In the first meeting of the project, in April 2019, ideas focused on desires, constraints and possibilities. Preliminary testing focused on what is needed for a functioning guitar, which naturally influences architectural design possibilities for the venue. Various tasks are now under waytesting, recalibrating, rethinking, 3D modeling [13] — and various stakeholders who will help facilitate fabrication and assembly are now on board. We anticipate this venue will exemplify how architecture can have a highly significant effect on the character, power and relevance of performance, adding layers of meaning and expression for both performer and audience [14].

\section{References and Notes}

1. Jim Lutz, "Transpositions: Architecture as Instrument/Instrument as Architecture," in Mikesch W. Muecke and Miriam S. Zach, eds., Resonance: Essays on the Intersection of Music and Architecture (Ames, IA: Culicidae Architectural Press, 2007).

2. Helen Lancaster et al., Redefining Places for Art: Exploring the Dynamics of Performance and Location (Brisbane, Australia: Griffith University, Queensland Conservatorium Research Centre, 2010).

3. Bluebottle, "Quartette Haus," Arch Daily (28 December 2013): www .archdaily.com/462308/quartette-haus-bluebottle (accessed 29 February 2020).

4. Rianne Wilschut, Close Encounters: Chamber Music in Small Venues $(\mathrm{PhD}$ thesis, Griffith University, Brisbane, Australia, 2018).

5. Vanessa Tomlinson, "On Listening: A Universe of Sound," Contemporary Music Review 36, Nos. 1-2, 5-14 (2017).

6. Barry Blesser and Linda-Ruth Salter, Spaces Speak: Are You Listening? Experiencing Aural Architecture (Cambridge, MA: MIT Press, 2009).

7. Martin Barker, "Live at a Cinema Near You: How Audiences Respond to Digital Streaming of the Arts," in Jennifer Radbourne, Hilary Glow and Katya Johanson, eds., Audience Experience: A Critical Analysis of Audiences in the Performing Arts (Bristol, U.K.: Intellect Ltd, 2013) pp. 15-35.

8. Wilschut [4].

9. Wilschut [4].

10. Cited in Sven Sterken, "Music as an Art of Space: Intersections Between Music and Architecture in the Work of Iannis Xenakis," in Muecke and Zach [1].

11. Sterken [10] p. 42.

12. Further examples of instrument-inspired architecture can be found in the online supplemental materials.

13. Current modeling specifications can be found in the supplemental materials.

14. Robert Kronenburg, "Live Architecture: The Design of Portable Buildings for Live Music Performance," Architectural Research Quarterly 14, No. 4, 304-316 (2010). 